\title{
The influence of nitrogen on the mechanical behaviour of multilayered coatings
}

\author{
M.T. Vieira*, C.M. Pereira, J.M. Castanho \\ ICEMS-Departamento de Engenharia Mecânica-Polo II, Faculdade de Ciências e Tecnologia da Universidade de Coimbra, \\ 3030 Coimbra, Portugal
}

\begin{abstract}
Multilayered films are a new kind of coating that belong to a more plentiful family of materials labelled as nanostructured materials. These kinds of coatings stand in the frontier of investigation in thin films for structural applications. In the present work, multilayered coatings with alternated layers of $\mathrm{W}-\mathrm{Ti}-(\mathrm{N})$ and $\mathrm{Ag}$ were deposited to be used as wear resistant surfaces. The association of the high hardness, wear resistance of $\mathrm{W}-\mathrm{Ti}-(\mathrm{N})$ layers [Proceedings of the Eleventh LAWPSP Symposium, SL1.1-SL1.7, Bombay, India (1998); Surf. Coat. Technol., 102 (1998), 50] and the good ductility of the silver ones is the guarantee of obtaining a better mechanical performant coating. However, to reach a satisfactory comprehension of the behaviour of the coatings in service a true understanding of some important properties is needed. For this reason, hardness, Young modulus, internal stresses and adhesion were evaluated, as well as function of the number and thickness of the layers. (C) 2000 Elsevier Science B.V. All rights reserved.
\end{abstract}

Keywords: Multilayered coatings; Young modulus; Adhesion; Hardness; Internal stresses

\section{Introduction}

Increasing the lifetime of a component by the deposition of a hard coating has always been one of the main goals of surface engineering. Towards this, different tungsten-based coatings have been deposited in order to improve the mechanical and corrosion properties of mechanical components.

Previous studies in $\mathrm{W}-\mathrm{N}$ sputtered coatings have shown that the solubility of nitrogen in tungsten can attain approximately 17 at.\%, for higher nitrogen content a tungsten nitride $\left(\mathrm{W}_{2} \mathrm{~N}\right.$ structure $)$ was deposited $[1,2]$. In order to improve the properties of $\mathrm{W}-\mathrm{N}$, pseudo-binary coatings like $(\mathrm{W}-\mathrm{Ti})-\mathrm{N}$ were researched [3].

However, the enhancement of the deposition tech-

\footnotetext{
${ }^{*}$ Corresponding author. Tel.: +351-39-790-700; fax: +351-39-790701.

E-mail address: teresa.vieira@mail.dem.uc.pt (M.T. Vieira).
}

niques associated to materials and surface engineering knowledge has given rise to the envisaging of a new kind of 'non-homogeneous' coatings: multilayered coatings. The reason for such an effort can be seen in the unusual and often singular properties of these kinds of coatings. In fact, coatings composed of periodically alternated layers of different materials present mechanical properties that are not just the combination of those presented by individual layers. Up to now, major research has been concerned with the improvement properties using the nanostructured multilayers; considering these coatings as homogeneous materials (very short period). Few works have dealt with submicron scale coating, which cannot theoretically be considered as being homogeneous coatings. However, these coatings could contribute to increasing wear performance relative to ordinary monolayer coatings.

The present paper is an attempt to try to evaluate the mechanical properties, such as hardness, Young's modulus, by a depth-sensing test, concerning the influ- 
ence of nitrogen in multilayered coatings with $5.5 \mu \mathrm{m}$ thickness, constituted of a pseudo-binary (W-Ti)-N hard layers with a low ductile silver layer in between. Finally, the influence of the ductile layers on residual stresses and adhesion of the coatings were also determined as a function of the thickness and the number of layers.

\section{Experimental procedure}

$\mathrm{W}-\mathrm{Ti}-(\mathrm{N}) / \mathrm{Ag}$ multilayered coatings were deposited using a d.c. reactive magnetron sputtering equipment computer controlled, from alternating $\mathrm{W}-\mathrm{Ti}$ and $\mathrm{Ag}$ targets. The detailed experimental conditions are: ultimate vacuum pressure $10^{-4} \mathrm{~Pa}$, etching pressure 0.15 $\mathrm{Pa}$, deposition pressure $0.3 \mathrm{~Pa}$, substrate bias $-70 \mathrm{~V}$, substrate rotation $23 \mathrm{rev}$./min, silver and $\mathrm{W}-\mathrm{Ti}$ target power density of $1.5 \times 10^{-2}$ and $1.1 \times 10^{-1} \mathrm{~W} / \mathrm{mm}^{2}$ and the interelectrode distance of 65 and $90 \mathrm{~mm}$, respectively. The film were deposited on M2 (AISI) substrates quenched and tempered to $9.2 \mathrm{GPa}$ of hardness. Immediately before deposition and after polishing, to an average roughness $\left(R_{a}\right)$ of $50 \mathrm{~nm}$, the substrates were ion cleaned. After previous studies of the deposition rate of each target material, the sputtering conditions were controlled to obtain coatings with 5.5 $\mu \mathrm{m}$ of total thickness. The ductile layer (Ag) presented $80 \mathrm{~nm}$ thickness and the total number of layers of each coating were 3,17 and 33. As-deposited film structures were detected by $\mathrm{X}$-ray diffraction using $\mathrm{Co}\left(\mathrm{K}_{\alpha}\right)$ radiation, in $\theta-2 \theta$ Bragg-Brentano mode. The global chemical composition of the coatings was evaluated by electron probe microanalysis (model Camebax SX50). The morphologies of the coatings were characterised by conventional scanning electron microscopy (SEM) using a cross-section technique. The residual stresses of the coatings were measured by a beam bending deflection technique based on the Stoney expression, using carbon steel plates $0.50 \mathrm{~mm}$ thick substrates. The hardness and Young modulus of the coatings were measured using micro-indentation hardness equipment (Fischerscope H100). Loads of 50, 100, 200, 300, 500 and $1000 \mathrm{mN}$ were applied and the load vs. indentation depth was continuously monitored. Due to the material heterogeneity of multilayered coatings, the hardness value and Young's modulus (expression 1) as a function of the number of layers is expressed for the same corrected indentation depth $\left(h_{p c}\right)$ [4].

$E=\frac{\left(1-v^{2}\right) \cdot \sqrt{\frac{\pi}{24.5}}}{2 \cdot h_{p c} \cdot\left(\frac{\mathrm{d} h_{p c}}{\mathrm{~d} p}-C_{0}\right)-\frac{\left(1-v_{i}^{2}\right)}{E_{i}} \cdot \sqrt{\frac{\pi}{24.5}}}$

Where $\mathrm{d} h_{p c} / \mathrm{d} p$ is the compliance, $C_{0}$ is the compliance associated to the equipment, $E_{i}$ and $v_{i}$ are Young's modulus and Poisson's ratio of the indentor, respectively, and $v$ the Poisson's ratio of the coating.

The adhesion of the coatings were evaluated by scratch-test (CSEM-Revetest) using a progressive normal load ranged from 0 to $80 \mathrm{~N}$ with a load/displacement ratio of $10 \mathrm{~N} / \mathrm{mm}$ [5]. The adhesive failures were observed by optical microscopy with a magnification of $100 \times$.

\section{Results and discussion}

Among the films produced, two different as-deposited structures were detected as a function of nitrogen/argon ratios. For low values of $\mathrm{N}_{2} / \mathrm{Ar}$ the coatings (class I) were identified as having a b.c.c. structure, which is equal to pure $\mathrm{W}$ or $\mathrm{W}$ with nitrogen in interstitial solid solution [1]. When nitrogen has attained high values (class II) $(\mathrm{TiW}) \mathrm{N}_{1-x}$ can be detected. This suggests that the $\mathrm{W}$ and Ti have mutual solubility. TiN and (WTi) ${ }_{2} \mathrm{~N}$ are f.c.c. isomorphic phases, but comparing the $d$-values of the films obtained with ICDD 38-1420 (TiN) $d$-values, the adjustment is better than ICDD 25-1257 $\left(\mathrm{W}_{2} \mathrm{~N}\right)$.

The chemical composition of these two classes of coatings is summarised in Table 1. In spite of the target composition $\left(\mathrm{W}_{50} \mathrm{Ti}_{50}\right)$, the films of class $\mathrm{I}$ are richer in tungsten than titanium. This behaviour confirms what was observed in films deposited by sputtering of multicomponent targets, constituted by elements of different atomic weights [6-8]. The coatings are enriched with higher atomic weight elements in disfavour of lighter ones. Due to the reactivity of titanium to nitrogen, the

Table 1

Chemical composition and adhesion of the coating

\begin{tabular}{|c|c|c|c|c|c|c|c|c|}
\hline \multirow{2}{*}{$\begin{array}{l}(\% \text { at. }) \\
\text { Layers }\end{array}$} & \multicolumn{4}{|c|}{ Low nitrogen content - Class I } & \multicolumn{4}{|c|}{ High nitrogen content - Class II } \\
\hline & $\begin{array}{l}\mathrm{W} \\
\text { (\% at.) }\end{array}$ & $\begin{array}{l}\mathrm{Ti} \\
\text { (\% at.) }\end{array}$ & $\begin{array}{l}\mathrm{N} \\
\text { (\% at.) }\end{array}$ & $\begin{array}{l}L c_{2} \\
(\mathrm{~N})\end{array}$ & $\begin{array}{l}\mathrm{W} \\
\text { (\% at.) }\end{array}$ & $\begin{array}{l}\mathrm{Ti} \\
\text { (\% at.) }\end{array}$ & $\begin{array}{l}\mathrm{N} \\
\text { (\% at.) }\end{array}$ & $\begin{array}{l}L c_{2} \\
(\mathrm{~N})\end{array}$ \\
\hline Monolayer (W-Ti-N) & 58.0 & 35.5 & 6.6 & 46 & 33.9 & 28.9 & 37.1 & 36 \\
\hline 3 layers & 53.5 & 34.8 & 11.6 & 36 & 33.4 & 27.8 & 38.8 & 54 \\
\hline 17 layers & 53.9 & 34.8 & 11.3 & 18 & 33.2 & 28.0 & 38.8 & 71 \\
\hline 33 layers & 51.1 & 35.0 & 13.9 & 19 & - & - & - & - \\
\hline
\end{tabular}




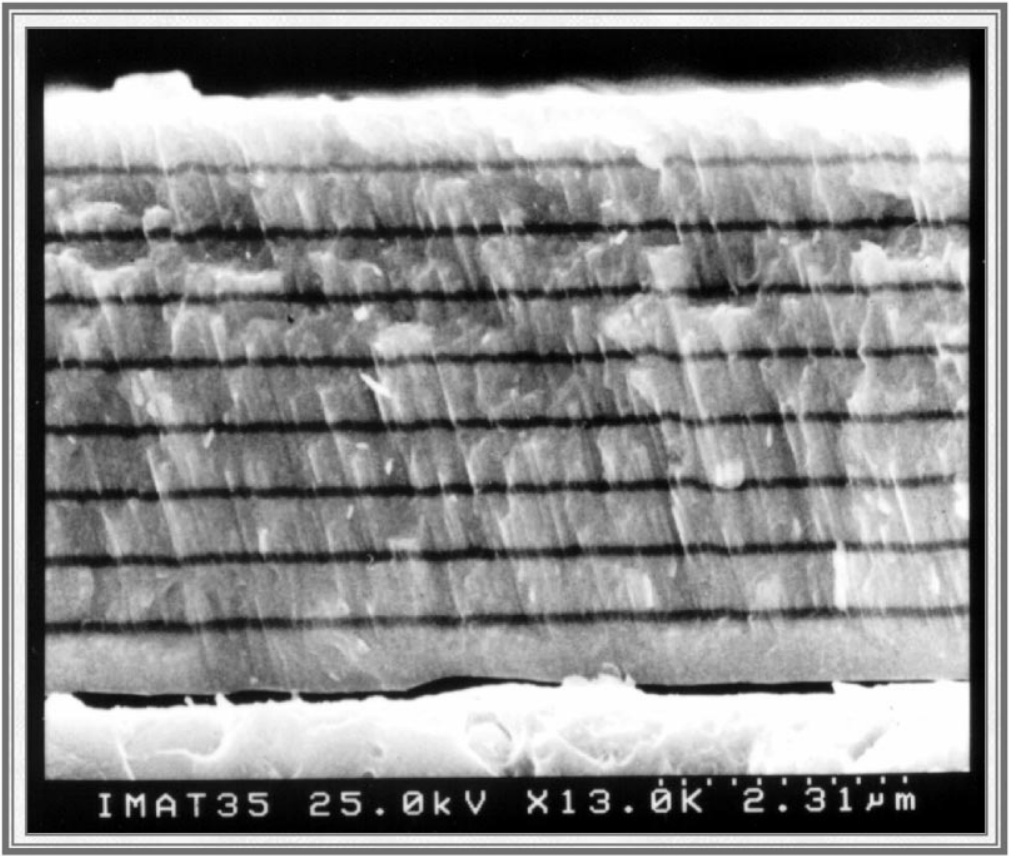

Fig. 1. Morphology of $\mathrm{W}-\mathrm{Ti}-\mathrm{N}$ monolayered coatings; left-low nitrogen content; right-high nitrogen content.

presence of high quantities of this element in $\mathrm{W}-\mathrm{Ti}$ based films (class II) leads to a decrease in tungsten/ titanium rate [9].

The presence of interlayers $(\mathrm{Ag})$ contributes to an abnormal increase of nitrogen content in the hard layers with the increase of number of layers in multilayered coatings. In fact, usually due to the target poisoning with nitrogen the initial material deposited on substrate has abnormal nitrogen content, but the overall chemical composition of the ensemble is not significantly affected. As the thickness of $\mathrm{W}-\mathrm{Ti}-\mathrm{N}$ layers decreases, that means the number of $\mathrm{Ag}$ layers increases, the nitrogen content in each layer of $\mathrm{W}-\mathrm{Ti}-\mathrm{N}$ approaches to the initial material so much that the thickness of the ceramic layer decreases.
The analysis of the silver thin film chemical composition obtained in a nitrogen atmosphere, similar to those used in the deposition of multilayered coatings, shows a very low quantity of nitrogen, probably adsorbed.

As monolayers, the $\mathrm{Ag}$ and the $\mathrm{W}-\mathrm{Ti}-\mathrm{N}$ films (see Fig. 1) presented compact morphologies. Due to the similar atomic weights of $\mathrm{W}$ and $\mathrm{Ag}$ it was difficult to find enough contrast in the multilayers to resolve different layers in the SEM by backscattering. In order to enhance the localisation, number, period and uniformity of the deposited multilayered coatings, Ti was used as a nanoscale layer in spite of Ag. Fig. 2 reveals a continuous and uniform nanoscale layer and these layers (interlayer) seem to hold the morphology of hard
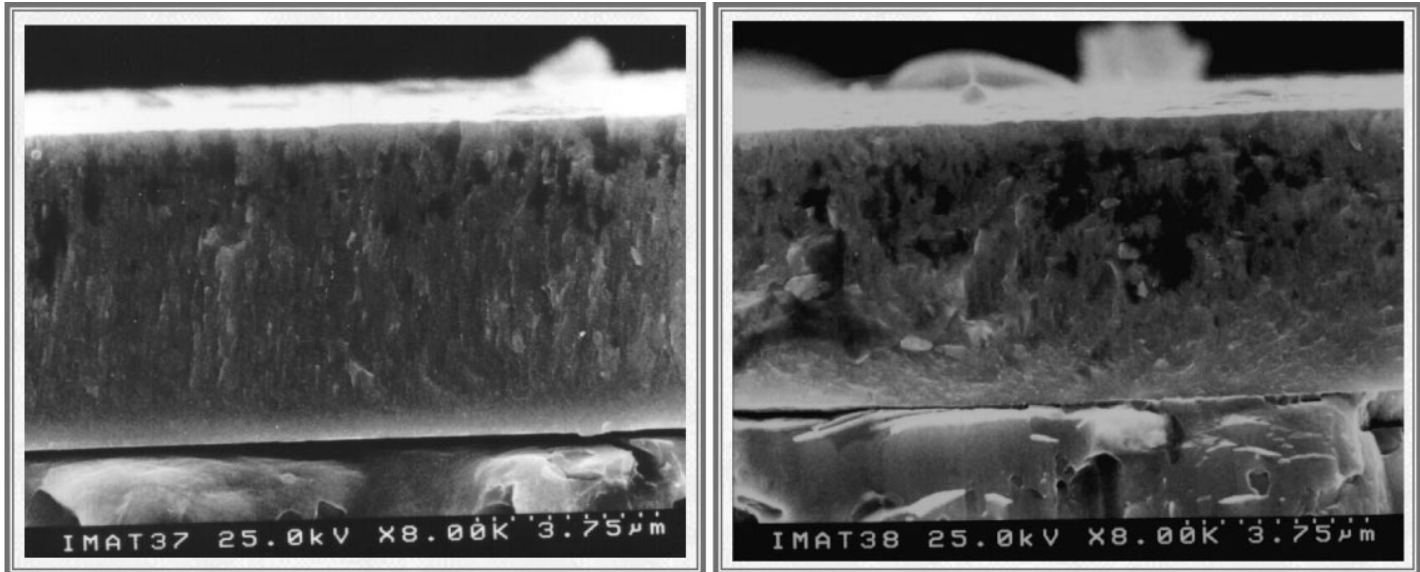

Fig. 2. Morphology of multilayered coating $\mathrm{W}-\mathrm{Ti}-\mathrm{N} / \mathrm{Ti}$. 

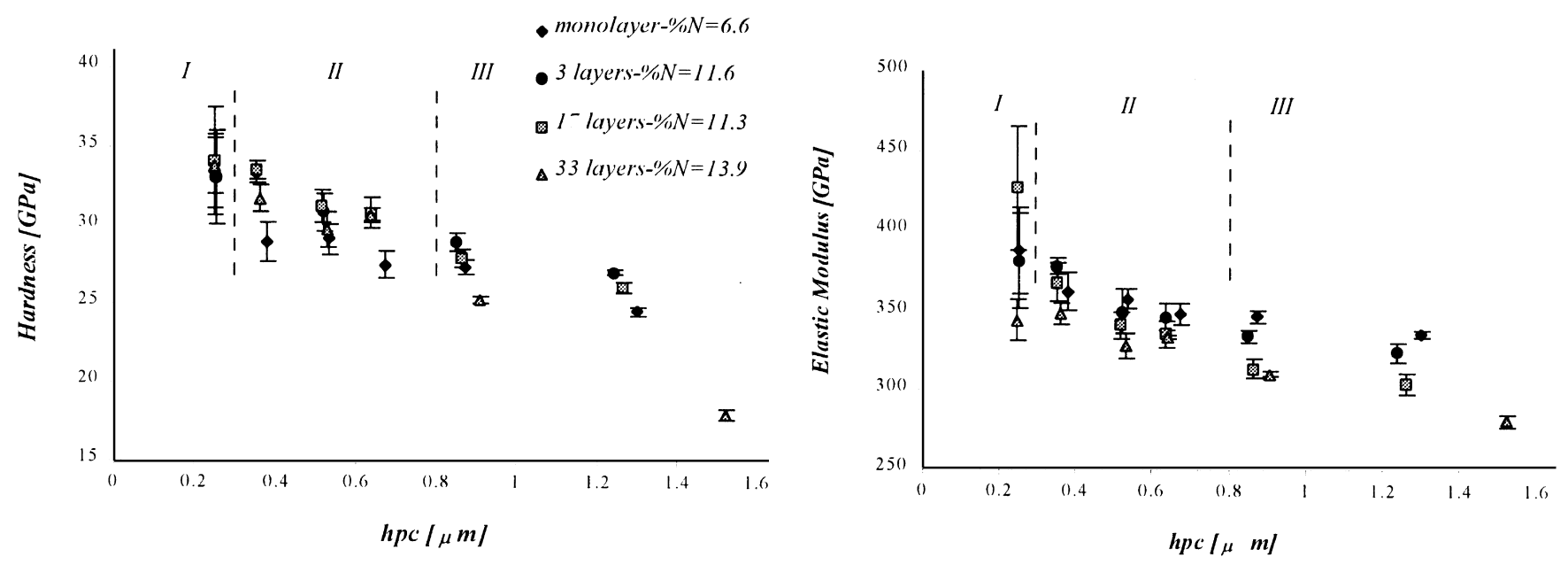

Fig. 3. Coating hardness and Young's modulus as a function of number of layers - Class I.

materials layer. The variation of the nitrogen content in the hard layer does not produce any change in the morphology.

The results of ultra-microhardness measurements on as-deposited coatings are expressed in Figs. 3 and 4. Those figures present the evolution of the hardness and Young's modulus as a function of the correct indentation depth $\left(h_{p c}\right)$, for coatings with number of layers. In both cases, the curves present three different zones: zone I, shows scattering of hardness values due to the low applied load $(50 \mathrm{mN})$; zone II, where the hardness values are independent of the depth and zone III, where the hardness decreases due to the influence of the substrate. The same evolution was verified in the Young modulus. The presence of titanium in a hard class I monolayer allows for hardness values (29 GPa) lower than those obtained in the $\mathrm{W}-\mathrm{N}$ system with a similar quantity of interstitial nitrogen (35 GPa) [1]. Nevertheless, in class II the presence of titanium seems to decrease the hardness values, $41 \mathrm{GPa}$ against $\leq 32$
$\mathrm{GPa}[1,10]$. (The hardness values disposable in the literature for this coating are obtained using classical microhardness equipment and should perhaps integrate the substrate effect.) The as-deposited silver shows a hardness of $2 \mathrm{GPa}$, double the value of hard bulk silver, and characteristic of sputter-coated films.

For both classes of hard layers the multilayer hardness is not strongly dependent on the number of layers. When the hard layer is of class I, the presence of ductile layers seems to contribute to a light increase in hardness (13\%). This behaviour must be attributed to the incorporation of nitrogen during the deposition of (W-Ti)-N layers, as is demonstrated in films with 3 and 17 layers of the same nitrogen content, where hardness values are similar (Fig. 3). But for class II the effect is the opposite, a decrease of $12 \%$ in 17 layers can be observed.

The residual stress, at room temperature, in the monolayered $\mathrm{W}-\mathrm{Ti}-\mathrm{N}$ coating is highly compressive $\left(\sigma_{\text {int }}=-7.75 \mathrm{GPa}\right)$, but the presence of a very thin $\mathrm{Ag}$
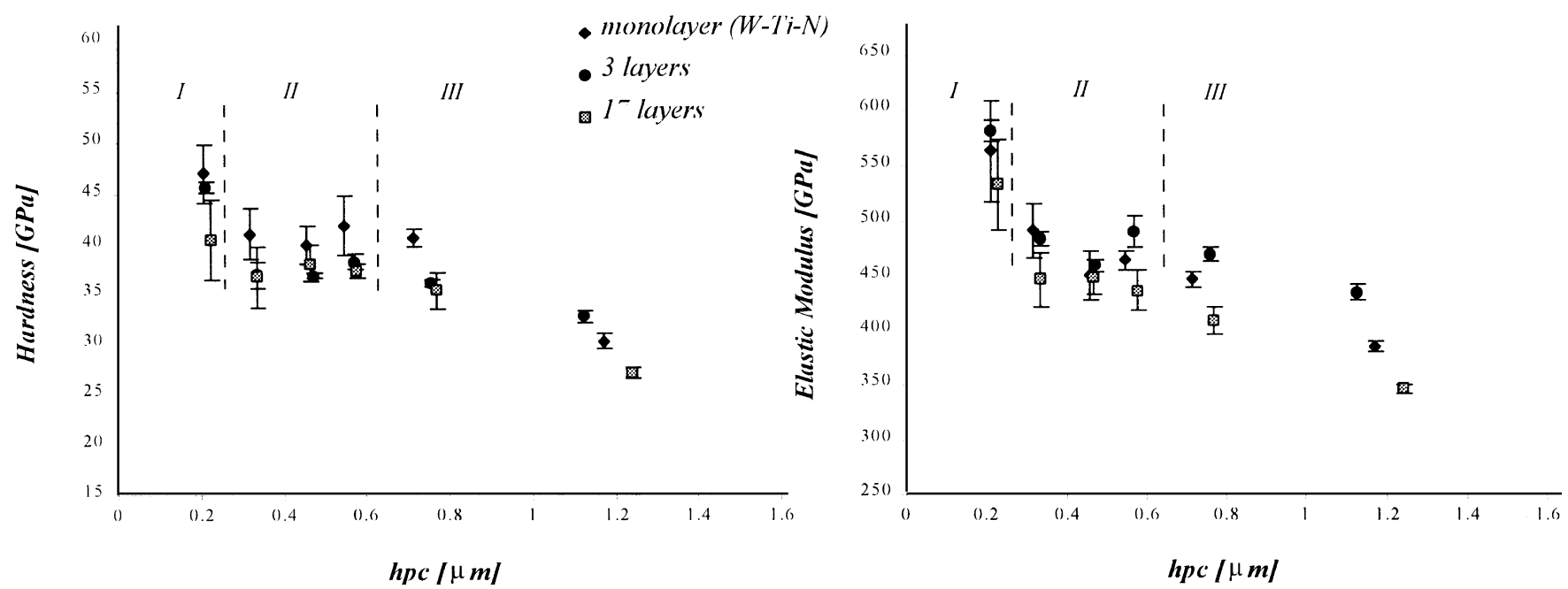

Fig. 4. Coating hardness and Young's modulus as a function of number of layers - Class II. 
layer of $80 \mathrm{~nm}$ reduces drastically the internal stresses of the multilayered class II coatings $\left(\sigma_{\text {int }}=-4.16 \mathrm{GPa}\right)$. However, there is no decrease in the internal stresses with the increase of the number of ductile layers (17 layered coatings presents $\sigma_{\text {int }}=-4.44 \mathrm{GPa}$ ).

The scratch test is one of the most used techniques to evaluate the adhesion of the coatings to substrate or between layers in multilayered coatings. This characteristic is mainly important when the component is underloaded. In Table 1 the $L_{c 2}$ values (adhesive critical load) of the coatings are summarised.

In class I, the $L_{c 2}$ values of the multilayered coatings decrease significantly compared with the values of the monolayer coating, as referred, perhaps due to increase of nitrogen content with the increase of the number of silver layers.

The class II multilayered coatings shows spalling to $L_{c 2}$ values as high as the number of layers presented in the coatings ( $L_{c 2}$ value can surpass $70 \mathrm{~N}$ for coatings with 17 layers). The adhesion collapse of the coating is always in the interface coating/substrate and the coating with 33 layers showed no adhesion at all.

\section{Conclusions}

Although the presence of a ductile layer of silver in multilayered coatings $\mathrm{W}-\mathrm{Ti}-\mathrm{N} / \mathrm{Ag}$ with low nitrogen content worsen the coating's performance, the introduction of ductile layers in the ceramic $\mathrm{W}-\mathrm{Ti}-\mathrm{N}$ coating do not affect the hardness but lead to an important increase of adhesion of the film to the substrate. In fact, multilayered coatings with eight layers of silver with $80 \mathrm{~nm}$ of thickness each (17 layers in total) presented a $L_{c 2}$ value double that of the $\mathrm{W}-\mathrm{Ti}-\mathrm{N}$ monolayered coating.

Finally, a single $80 \mathrm{~nm}$ thick silver layer is enough to promote a substantial decrease of the state of compressive stress of the multilayered coatings.

\section{References}

[1] J.M. Castanho, M.T. Vieira, NordTrib '98: Proceedings of the Eighth Internacional Conference on Tribology, 1998 p. 889.

[2] A. Cavaleiro, M.T. Vieira, F. Ramos, J.P. Dias, Thin Solid Films 290/291 (1996) 238-242.

[3] R.C. Cammarata, J.C. Bilello, A.L. Greer, K. Sieradzki, S.M. Yalisove, MRS Bull. 24 (2) (1999) 34-38.

[4] A. Trindade, J. Test. Eval. 22 (4) (1994) 365-369.

[5] B.S.I., Determination of Adhesion by Scratch-Test, BSI DD ENV 1071-3, 1994.

[6] P. Sigmund, J. Vac. Sci. Technol. 214 (1977) 152.

[7] H.F. Winters, J. Vac. Sci. Technol. 3 (1982) 493.

[8] B. Trindade, M.T. Vieira, E. Bauer-Grosse, Acta Mater. 46 (5) (1998) 1731-1739.

[9] I.J. Raaijmakers, T. Setalvad, A.S. Bhansali, B.J. Burrow, L. Gutai, K. Kim, J. Electron. Mater. 19 (11) (1990).

[10] T. Hurkmans, T. Trinh, D.B. Lewis, J.S. Brooks, W.D. Munz, Surf. Coat. Technol. 76/77 (159/166) (1995) 2. 